\title{
Conspecific neighbors and kinship influence egg cannibalism in the green lacewing, Chrysoperla carnea (Stephens)
}

\author{
Mubasshir Sohail" (D), Qadeer Ahmed Soomro, Muhammad Usman Asif, Imran Rauf and Raza Muhammad
}

\begin{abstract}
Background: Chrysoperla carnea (Stephens) (Neuroptera: Chrysopidae) is an illustrious predator that performs cannibalism upon facing small and defenseless conspecifics. Eating preference of $C$. carnea larvae was investigated between conspecific and host (Sitotroga cerealella) eggs. Early instars of $C$. carnea express significant preference toward conspecific eggs over host eggs. Experiments were carried out to examine the role of conspecific neighbors in execution of cannibalistic decision. These cannibalistic behaviors of larvae were also investigated through locomotion bioassays using the video tracking software ANY-maze ${ }^{\circledR}$.

Results: Larvae commit low egg cannibalism when alone but express higher cannibalism in the presence of conspecific larvae in the neighborhood. The role of relatedness in egg cannibalism was investigated when larvae were offered a choice between conspecific eggs from related and unrelated parents. Larvae did a discrimination between eggs of their own parents and those of other parents.
\end{abstract}

Conclusion: Behavioral bioassays showed attraction toward conspecific eggs and the eggs of unrelated parents. This study emphasizes the significance of informational and descriptive cues that modulate the cannibalistic expression in C. carnea.

Keywords: Chrysoperla carnea, Cannibalistic behavior, Locomotion bioassay, Tracking

\section{Background}

Cannibalism is usually supposed as an abnormal behavior of killing and ingestion of all or part of conspecifics which was generally ignored until the 1970s (Simpson et al. 2018). Since last several decades, it has been revealed that cannibalism is a prevalent feeding scheme that can be induced by ecological factors such as a low food availability and a high population density (Vijendravarma et al. 2013; Arvaniti et al. 2019). Cannibalism occurs generally across many taxa in an environment, and it is supposed to lessen the real numbers where cannibalism occurred because the data are not from systematic surveys (Richardson et al. 2010). Cannibalism involves

\footnotetext{
*Correspondence: mubasshirsohailroy@gmail.com

Plant Protection Division, Nuclear Institute of Agriculture, Tando Jam, Pakistan
}

fitness benefits and costs for individuals; the victim generally incurs only costs, unless by being consumed it can uplift its inclusive fitness. The primary benefit for cannibal is to get food and kill a potential competitor (Van den Beuken et al. 2019). Furthermore, the cannibal may get a better balance of nutrients that are essential for growth and development than who consume other heterospecifics (Tigreros et al. 2018).

Predatory insects are more common in consumption of their conspecifics where they are naturally allowed to kill and consume live prey due to their physical and physiological adaptation (Simpson et al. 2018). Predators habitually target weak life stages, such as eggs or younger nymphs/larvae, possibly to avoid injury. However, this behavior emanates with several other possible costs, such as injuring and killing siblings, thereby lessening the indirect fitness of the cannibal, as well as heightening the 
chances of acquiring the infection of deleterious parasites and pathogens (Pizzatto and Shine 2011).

Organisms encounter conspecifics for committing filial cannibalism by two possible mechanisms. First, phenotypic cues they possessed help to kin recognition directly (e.g. paper wasp (Ropalidia marginata), honeybees (Apis mellifera) and desert isopods (Hemilepistus reaumuri) can differentiate between sibling and non-sibling using these cues or labels like odors (Neff and Sherman 2003). Second, conspecific recognition may be done using association between probabilities of encountering offspring and non-phenotypic cues (Lissåker and Svensson 2008). For example, female red flour beetle, Tribolium castaneum, uses locational cues to identify conspecifics. Before getting engaged in cannibalism, they leave the area into which their offspring disperse, thereby lowering the possibility of eating their own young's (Pfennig 1997). If the dispersal is limited, existence of reproductive fellows in the close neighborhood may act as a cue to recognize their own offspring (Manica 2004). Regardless of kin recognition, offspring that have less likelihood of survival may be more prone to cannibalized by parents, as this let the parents to cannibalize some of them later, when condition may become more adverse, instead of losing all at once.

The expression of cannibalistic behavior in generalist predator such as the green lacewing, Chrysoperla carnea (Stephens) (Neuroptera: Chrysopidae), has been investigated toward conspecific eggs by larval instars. Initially, the present hypothesis tested was that whether larvae commit egg cannibalism in the presence of host S. cerealella eggs or not, and is there any significance in their consumption. Furthermore, an increase in the egg cannibalism rate of $C$. carnea larvae was tested, when conspecific larvae were present in the neighborhood. Also, examined whether direct association influences egg cannibalism when larvae offered related and unrelated conspecific eggs. Keeping in view of the high searching aptitude of $C$. carnea larvae, behavioral locomotion bioassays were performed to better understand the filial relationship and cannibalistic preference.

\section{Methods}

\section{Green lacewing-collection and rearing}

C. carnea adults were captured from Tandojam (location: $25.4203^{\circ} \mathrm{N}, 68.5445^{\circ} \mathrm{E}$ ) during year 2019 , as commonly found in cotton, sugarcane and mango orchard. Specialized LED-based light traps were installed in various fields to attract lacewing trichromatic vision (Gaglio et al. 2017). The collected adults were transferred to rearing cages $(23.5 \times 23.5 \times 20.5 \mathrm{~cm})$ made of crystal acrylic sheets $(1 \mathrm{~cm}$ gauge). Adults were reared on an artificial diet consisting honey, sugar, yeast and distilled water
(1:2:1:2), replaced daily and supplied ad libitum (Sohail et al. 2018). Rearing cages were provided black linen cloth at the top for egg laying (Sohail et al. 2019). Collected $C$. carnea eggs were transferred in black cover cloth and fed on frozen Angoumois grain moth, Sitotroga cerealella eggs (Pasini et al. 2018). On hatching of first instars, larvae were sealed in 2 inches polypropylene transparent straw/tubes with three pin aeration holes to avoid cannibalism (Sohail et al. 2019). Pupae were then separated from tubes and transferred on glass Petri plates $(6 \mathrm{~cm}$ diameter) for emergence. The life stages were maintained at $25 \pm 1{ }^{\circ} \mathrm{C}$ and $60 \pm 5 \% \mathrm{RH}$ and 15:9 (L/D) for further studies.

\section{Cannibalism of $C$. carnea}

Experiment 1, conducted during 1-2 October 2019, tested cannibalism rates in different instars of C. carnea. Aim was to produce an independent test to compare the rate of cannibalism of each instar. All the 3 instars were kept in polypropylene transparent tubes $(5 \mathrm{~cm}$ long) and starved for $10 \mathrm{~h}$ to standardize their appetite (Sohail et al. 2020). Starved 1st, 2nd and 3rd instar larvae received 20, 40 and 60 conspecific eggs in Petri dishes $(60 \times 15 \mathrm{~mm})$, respectively. Eight individuals of each instar were assessed for their cannibalism. At the end of 24-h isolation, the cannibalism rate of each individual instar was measured.

\section{Cannibalism in the presence of host}

Experiment 2, conducted during 14-18 October 2019, tested whether the presence of host eggs modulates the expression of egg cannibalism. Egg cannibalism of each instar was evaluated, when S. cerealella eggs were also provided in equal amount. The arena consisted of $9 \mathrm{~cm}$ Petri dish with 90-mm filter paper at base. A lid over the arena contained the mesh net (mesh size $=1.15 \mathrm{~mm}^{2}$ ) in the center for air flow. The arena was provided C. carnea eggs in one half and S. cerealella eggs in another half. After $24 \mathrm{~h}$ of starvation, the different numbers of egg ratio (C. carnea: S. cerealella) offered to each larval instar were: 1st instar 15:15; 2nd instar 30: 30; and 3rd instar 45: 45. Eight individuals of each instar were assessed for their cannibalism. Under the hypothesis of decreasing cannibalism rate in the presence of host eggs, data were recorded of egg cannibalism within $24 \mathrm{~h}$.

\section{Cannibalism in competition}

Experiment 3, conducted during 11-22 November 2019, tested whether $C$. carnea larvae exhibit greater rate egg cannibalism when they found company of conspecifics in their neighborhood. Another aim was to characterize the relationship between egg cannibalism by focal larva with respect to the number of neighboring larvae. On day 
0 (10 November), individual C. carnea larvae were isolated in 2 inches polypropylene transparent tubes with excess frozen $S$. cerealella eggs. Isolation was practiced to standardize the larval perception of native conspecific density before treatment. On day 1 (11 November), prior to place them in the arena, each separated individual was placed at starvation for $24 \mathrm{~h}$. The test arena comprised of a customized glass Petri plate $(60 \times 20 \mathrm{~mm})$ separated along diameter in equal half by a mesh net (mesh size $=1.15 \mathrm{~mm}^{2}$ ). Focal larvae was placed any side in the half, while other half either received 1, 2, 4 and 8 conspecific larvae $(N=8,8,8$ and 8 , respectively) or left empty as control $(N=8)$. S. cerealella eggs were provided to the larvae expect the focal larvae, which were given known amount of conspecific eggs to evaluate cannibalism rate. The mesh net prevented larvae from crossing over but permitted the focal larvae to sense neighboring conspecific larvae. Focal larvae were allowed to cannibalize the eggs for $24 \mathrm{~h}$. Cannibalized eggs were identified by their absence and empty or collapsed chorion. As C. carnea eggs hatched in about 3-4 days; thus, eggs couldn't have hatched during study. One-way analysis of variance, followed by HSD test, was used to compare egg cannibalism rate with different numbers of neighboring individuals. Paired $t$ test $(p>0.05)$ was used to compare all treatments with control.

\section{Filial cannibalism}

Experiment 4, conducted during 2-12 December 2019, aimed to evaluate the probability of filial cannibalism modifies the manifestation of cannibalism. Egg cannibalism of $C$. carnea larvae was tested on eggs from their own parents and eggs from other random couple. Here the tested hypothesis was to check the cannibalism choice of the larva between conspecific eggs of related and unrelated parents. Three arenas were constructed to execute this experiment. Each one constructed by the method described for experiment 2 . The 2 nd instar larvae were placed in each arena for $24 \mathrm{~h}$ isolation to standardize with arena surroundings. After isolation, different amounts of eggs offered to larva in each arena were: 1 st arena 30 conspecific related eggs; 2 nd arena 30 conspecific unrelated eggs; and 3rd arena 15 conspecific related eggs +15 conspecific unrelated eggs. In 3rd arena, related and unrelated eggs offered to larva at different halves. This experiment was replicated 8 times with 36 number of larvae. After $24 \mathrm{~h}$, numbers of related and unrelated eggs cannibalized by the larvae were counted.

\section{Behavioral response}

The olfactory behavioral response was examined during 16-28 December 2019, intended to track C. carnea larvae in a dual choice Y-maze bioassay (Fig. 1). The maze was



made up of glass with three arms (one release; two novel). Novel arms were provided with wells for diet/treatment application. All arms were closed with 80 mesh sieve to avoid either escape of larva or to stick on diet/treatment. A single C. carnea larva was released through the release arm and its behavior was observed for up to $10 \mathrm{~min}$. For each diet combination, 20 larvae were tested. After each bioassay, the maze was wash with soap and then with $70 \%$ ethanol and dried in an oven at $121^{\circ} \mathrm{C}$. The following 2 combinations were test: (1) C. carnea eggs vs. S. cerealella eggs; (2) eggs form related parents $v s$. eggs from unrelated parents. First combination was tested against 1st, 2nd and 3rd instar C. carnea larvae, while second was tested just 2 nd instar larva. Completely randomized design was used to analyze the data of 20 larvae per diet combination. Larval behavior was recorded with the digital camera (Nikon ${ }^{\circledR}$ D-5200, with Nikon lens $10-24 \mathrm{~mm}$ $\mathrm{f} / 3.5-4.5$, Tokyo, Japan) fitted at a height of $40 \mathrm{~cm}$ above the arena. Video recordings were analyzed using video tracking software (ANY-maze ${ }^{\circledR}$ 6.1, Stoelting CO, USA). The Y-maze arena apparatus was set to record readings of only novel arms. Path tracking, distance traveled, speed and time spent in each novel arm were recorded using 20 larvae of each instars. The novel arm where $C$. carnea larvae spent more than half of the total time was considered preferred and the other arm that retained the larvae less than half of the time was marked non-preferred.

\section{Statistical analysis}

Cannibalism rate of each instar was compared using one-way analysis of variance and HSD test. Difference in consumption of (C. carnea and S. cerealella) eggs and 
consumption of eggs (related and unrelated) was analyzed using paired $t$ test $(p>0.05)$ per instar. Likewise, in behavior response bioassay, difference in parameters (distance, time and speed) was analyzed using paired $t$ test $(p>0.05)$. All statistical analyses were performed using statistical software "SPSS", version 16.0.

\section{Results}

In experiment 1 , the significance difference $(\mathrm{f}=26.1$, $d f=23, p<0.00)$ was found in egg cannibalism of different larval instars of C. carnea (Fig. 2). Second and third instar larvae expressed 1.6 and 2.3-fold higher egg cannibalism, respectively, and found more voracious toward conspecific eggs than the first instar larvae.

In experiment 2 , in the presence of host eggs, the rate of egg cannibalism varied greatly with a significant difference among the first and second instar larvae (Fig. 3). Earlier instar larvae (first instar $(t=5.7, d f=14, p<0.00)$ and second instar $(t=3.5, d f=14, p=0.003))$ were committed significant egg cannibalism, regardless of the presence of host eggs, indicating the attraction to conspecific eggs was not influenced by the presence of host eggs. However, the third instar larvae were equally consumed conspecific eggs and host eggs $(t=-1.6, d f=14$, $p=0.132)$.

In experiment 3 , both second and third instar larvae were evaluated for egg cannibalism in the presence of conspecific larvae (Fig. 4). Lone focal second instar larvae expressed low egg cannibalism $(20.6 \pm 1.1)$. However, focal larvae in the presence of neighboring larvae 1, 2, 4 and 8 expressed 1.2, 1.3, 1.3 and 1.8-fold increase in egg cannibalism, respectively. Likewise, during the assay of third instar, focal larvae held alone continued to exhibit low cannibalism $(33.9 \pm 2.5)$, but those held in the presence of conspecific larvae 1, 2, 4 and 8 become 1.1, 1.3, 1.6 and 1.6-fold more cannibalistic, respectively. Egg cannibalism changed significantly with increase in numbers of neighboring larvae (second instar $=\mathrm{f}=31.6, d f=39$, $p<0.00$; third instar $=\mathrm{f}=23.6, d f=39, p<0.00)$. Results of comparison between control and each number of neighboring larvae were found significant in both (second and third) instar, except when held with single neighbor.

In experiment 4, nonsignificant difference was recorded in egg cannibalism when $C$. carnea larvae were held in two separate arenas for each type (related and unrelated) of eggs ( $p=0.736)$ (Fig. 5). However, conspecific eggs of the other parents (unrelated) were significantly more preferred to cannibalize than the eggs of the same parents (related) $(p<0.00)$.

\section{Behavioral response}

In the test combination of C. carnea eggs $v$ s. S. cerealella eggs, time proportion spent by the first instar of $C$. carnea in both novel arms was statistically similar $(t=0.14$, $d f=19, p=0.894)$ and no preference was found toward different eggs (Figs. 6 and 7). Likewise, nonsignificant difference was found in speed $(t=-0.79, d f=19, p=0.441)$ and as well as in the distance $(t=1.4, d f=19, p=0.187)$ traveled by first instars in both novel arms provided with C. carnea and S. cerealella eggs. However, behavioral

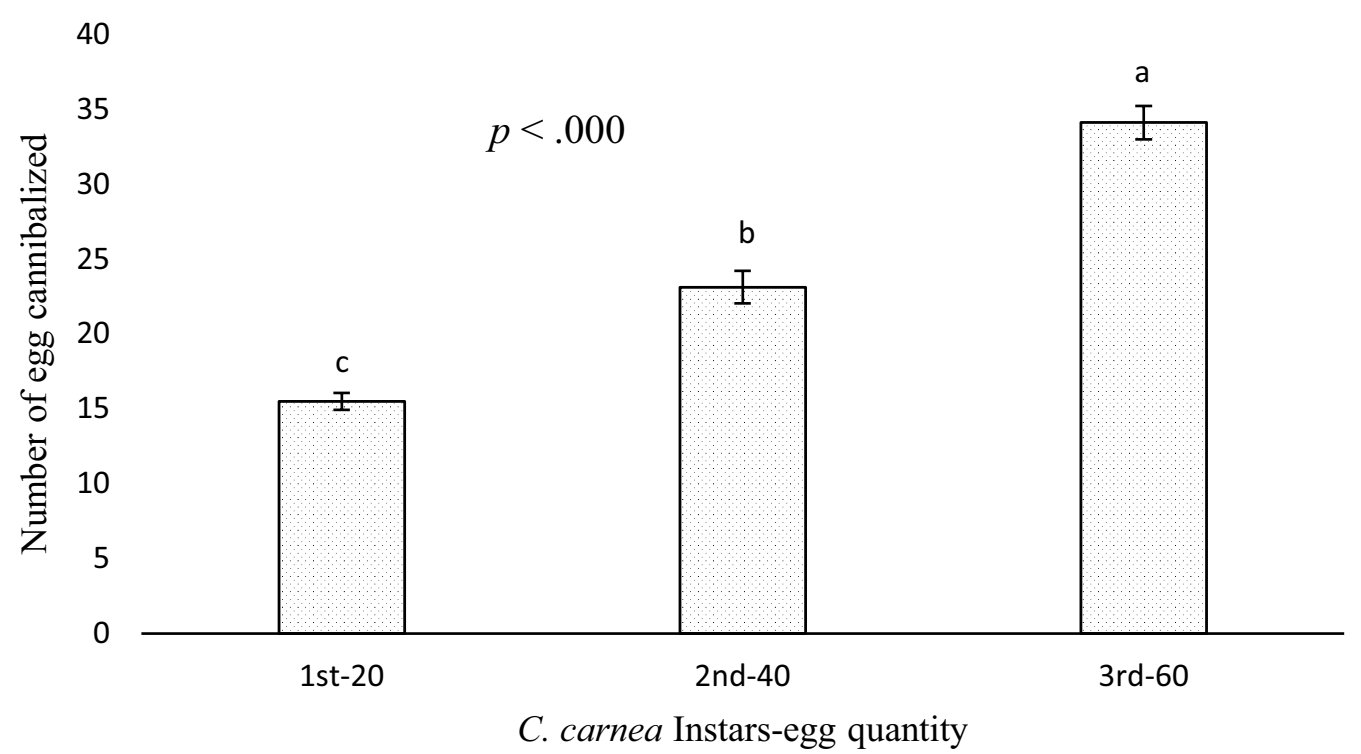

Fig. 2 Conspecific egg cannibalism by larval instars of C. carnea. Each bar represents mean egg consumption ( \pm SEM, where $N=8$ for each bar). Difference in letters above the bars indicates significant $(p<0.05)$ 


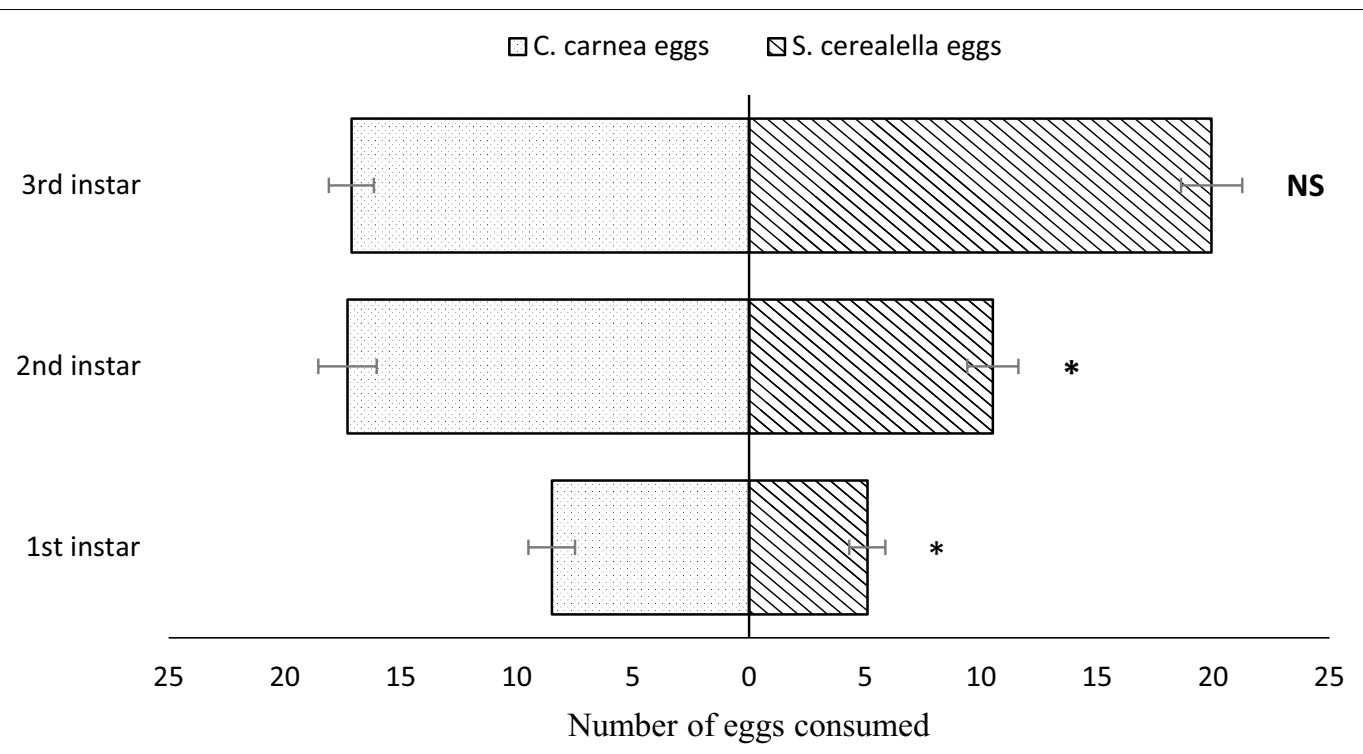

Fig. 3 Horizontal bars indicate average number of eggs consumed by specific C. carnea instars. All horizontal lines indicate \pm SEM with $N=8$ for each bar. Asterisk beside the bars indicates significant difference between consumed egg proportion of C. carnea or S. cerealella by C. carnea instars



preference to C. carnea eggs was recognized by the second and third instar larvae, where they spent more than half of the total time in the particular novel arm. Speed of second instar larvae remained similar in both novel arms $(t=-0.68, d f=19, p=0.502)$ but the significant difference was detected in third instar larvae $(t=7.9, d f=19$, $p<0.00)$. Distance traveled by second instar was significantly higher $(t=6.2, d f=19, p=0.00)$ in the novel arm provided with $C$. carnea eggs than the other arm with $S$. cerealella eggs, while nonsignificant difference was found in the distance traveled by third instar larvae $(t=0.8$, $d f=19, p=0.430$ ).

Furthermore, in the second (eggs from related parents vs. eggs from unrelated parents) test combination, second instar C. carnea larvae preferred eggs of unrelated parents over eggs of unrelated parents $(t=-13.06, d f=19$, 


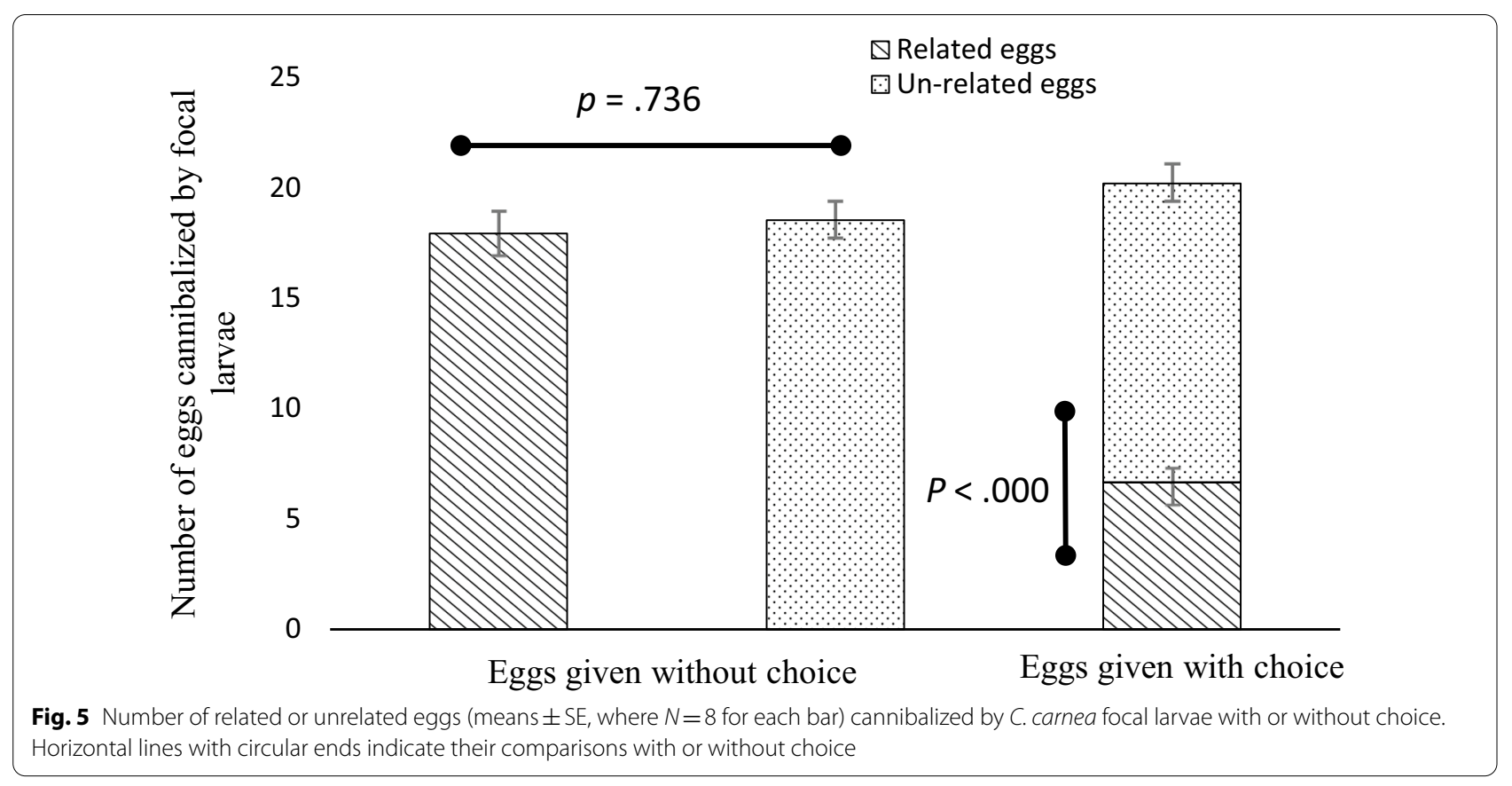

$p=0.00)$ (Figs. 8 and 9). Speed $(t=-2.03, d f=19$, $p=0.66)$ and distance $(t=0.56, d f=19, p=0.58)$ traveled in both novel arms were found similar.

\section{Discussion}

Cannibalism in C. carnea is a predominant phenomenon that can be assessed as to its significance for both the individual and the population. Keeping in view its nutritional need, a critical life stage of the larva is from hatching to invading of its debut prey. During that stage, larval mobility is comparatively low and tolerance to hunger is poor (Pitwak et al. 2016). After hatching, young larvae start scanning the instant surroundings that increase the probability of discovering their conspecific eggs. Three to four eggs per day may extend the likelihood of survival even in the absence of other prey. Therefore, larval searching may be significantly prolonged and with it, its probabilities of discovering other prey. Egg cannibalism reduces the number of developing individuals but also consider as a mean for enabling survival until the other prey is encountered rather than as providing diet for entire growth.

Nutritional requirements of a larval instar vary depending on the individual's stage of development that regulate the prey consumption in predator. In the present study, earlier instar C. carnea larvae cannibalized less eggs than did later instar larvae, as one would expect given the size difference among the larval instars. Furthermore, metabolism also typically increased in late instar larvae, this usually due to the insect's increased activity (Kerkut 2013)

In experiment 2, early instars (first and second) of $C$. carnea were committed egg cannibalism significantly more even in the presence of host eggs ( $S$. cerealella). Likewise, third instar larvae were equally consumed conspecific eggs and host eggs. Video tracking was used to assess their cannibalistic behavior. Lateral instars of $C$. carnea preferred to stick with the novel arm, containing conspecific eggs rather than host eggs. Similar observations were documented that some of insects prefer to eat conspecifics instead of natural food (Barros-Bellanda and Zucoloto 2005). This behavior may be triggered by the requirement of good food quality or by scarcity of high population density of potential competitors. Food is essential for living beings to continue life, but preference of conspecifics over natural food may have direct influence on increase insect fitness. Conspecific eggs are known to be more nutritious to developing larvae, who could consequently be helped by cannibalizing eggs when host or host eggs are rare or of poor quality (Gagné et al. 2002). The preference for conspecific eggs depicted that larvae can discriminate among different foods. Furthermore, cannibals are found to have prolonged survival, higher weight, higher rate of development and/or fecundity as compared to the non-cannibals (Tanahashi and Togashi 2009). Barros-Bellanda and Zucoloto (2001) reported that the pierid, Ascia monuste, cannibal larvae gain higher weight and survival rate than non-cannibal ones. Likewise, Mediterranean fruit fly, Ceratitis capitata 
I

Os $\quad-4 m 22 s$
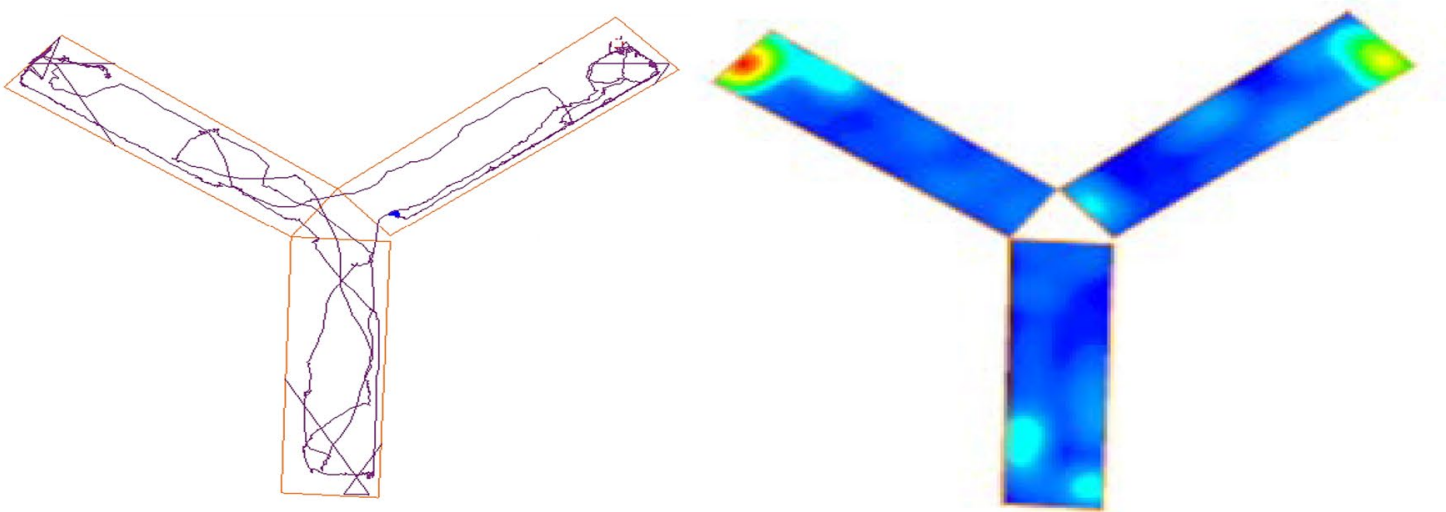

II.

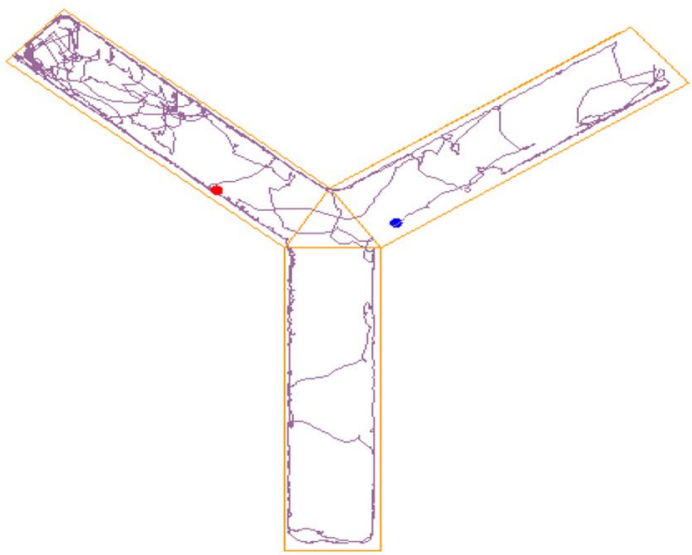

Os $-4 m 22 s$

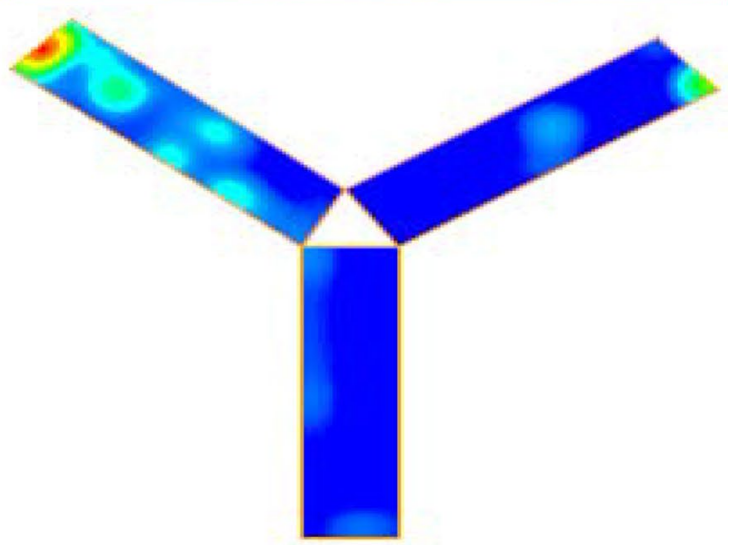

III.

Os $-4 m 22 s$


Fig. 6 Track (A) and heat (B) map visualizing the path followed and time spent by 1st (I), 2nd (II) and 3rd (III) instar individual C. carnea in movement area for ten minutes. Vertical arm is a release arm, where Y-maze provided with C. carnea eggs at left arm and of S. cerealella eggs at right arm. Blue and orange spots are starting and ending point, respectively. Data were analyzed using video tracking software (ANY-maze ${ }^{\circledR}$, Stoelting CO, USA) 


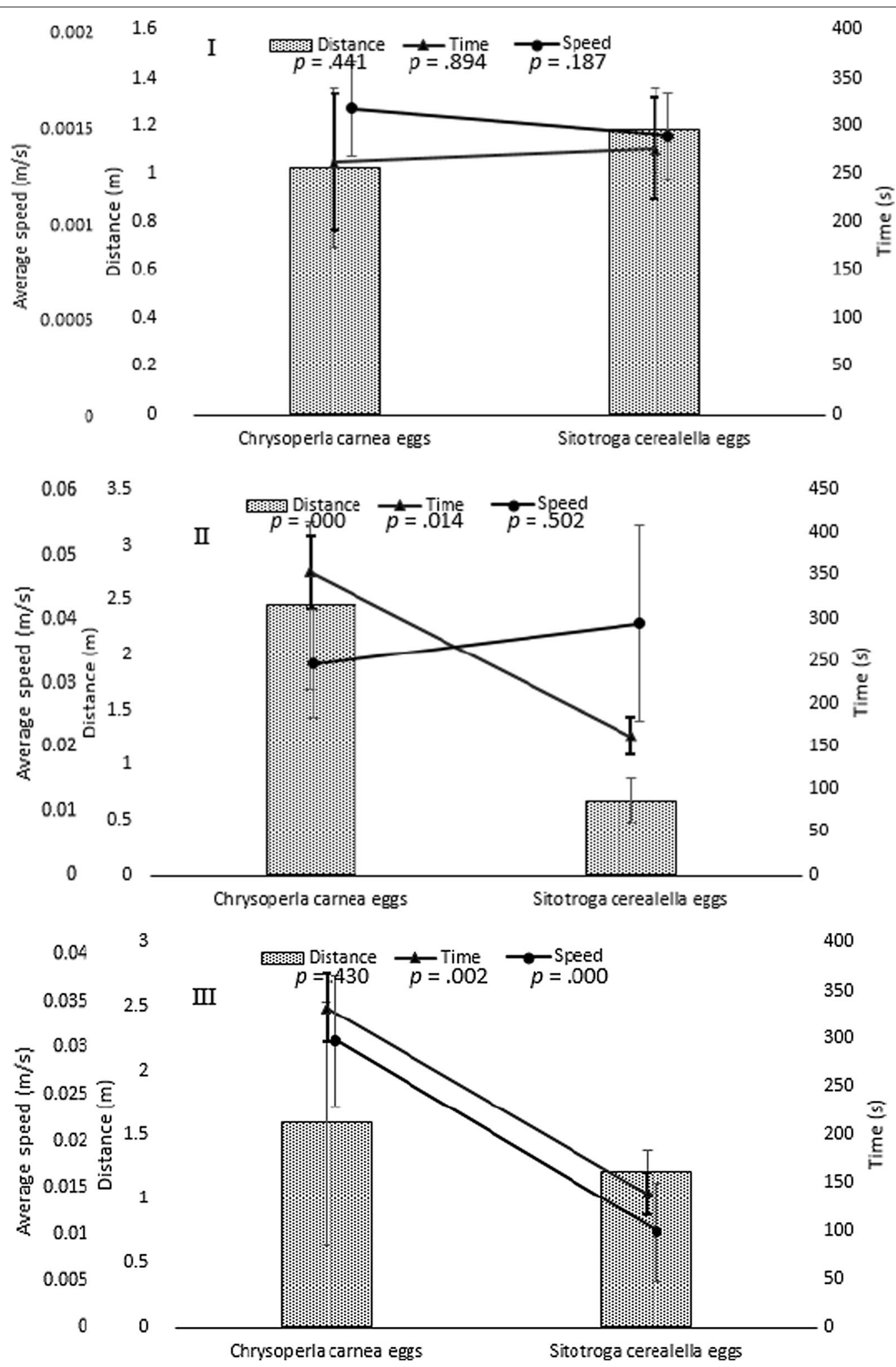

Fig. 7 Graph presents distance traveled (vertical bars) time (line with triangle ends) and speed (line with circular ends) of 1st (I), 2nd (II) and 3rd (III) instar C. carnea in movement area for ten minutes. All vertical lines indicate \pm SEM with $N=20$, where Y-maze provided with eggs of $C$. carnea and S. cerealella 


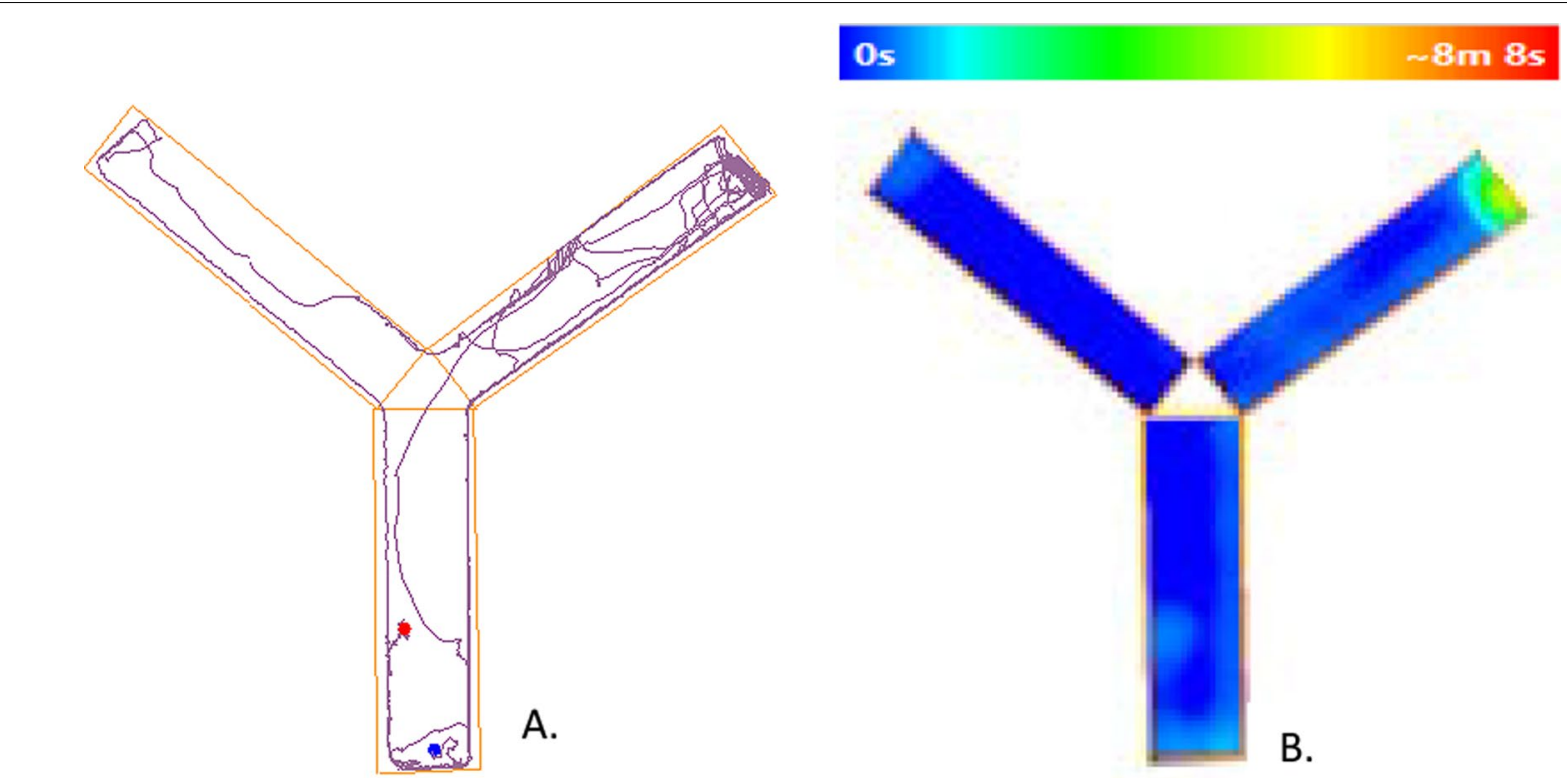

Fig. 8 Track (A) and heat (B) map visualizing the time spent of 2nd instar individual C. carnea in movement area for ten minutes. Vertical arm is a release arm. Y-maze provided with eggs of related parents at left arm and of un-related parents at right arm. Blue and orange spots are starting and ending point, respectively

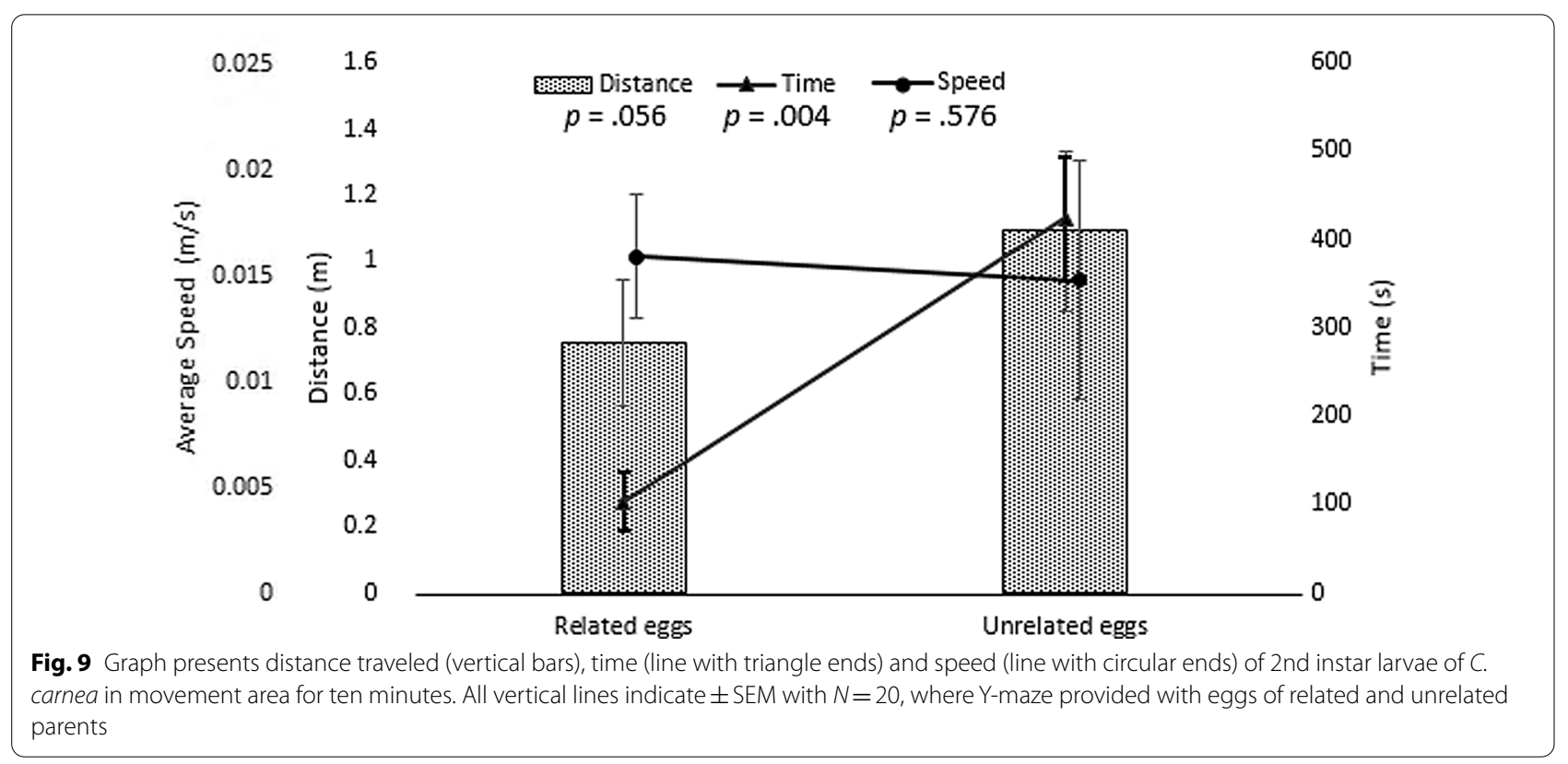

(Wiedemann) committed an egg or larval cannibalism to propitiate themselves in improved growth and development (Zucoloto 1993). This demonstrates that although natural food is present, insects may take their conspecifics for nutritional benefits. Regarding nonnutritional factors, cannibalism resultant from high population density. Individual that cannibalizes eliminates possible conspecific predator and a potential competitor (Polis 1981). Eating conspecifics preferably may lead to reduce the population size, which make food per capita more abundant, and increase the chances to survive and develop more rapidly. These reasons may involve in changing feeding preference to conspecifics instead of other food source. 
In experiment 3 , second and third instar larvae were found less cannibalistic when alone become highly cannibalistic in the presence of neighboring larvae. Committing of this cannibalism is usually due to amplified aggression for resource limitation when the density of cannibals is high (Wise 2006). Here, C. carnea larvae might use presence and absence of neighbors to assess the resource competition, challenged from other conspecifics in the future. In such case, $C$. carnea larvae would be more cannibalistic in the presence of conspecifics, because they are scared to get starve in future. The second possibility is, if the conspecifics consumed these eggs, they would gather more strength and power. So, being weak fellows, focal larvae would have low chances to survive under these circumstances. One more thing might have been hypothesized that nearby siblings could effect in the raised level of stress which may lead to elevated metabolism and consequently higher cannibalism.

Therefore, focal larvae should also be expected to respond to the neighborhood as it could be experienced by other conspecifics. Hence, the resource competition appeared in this experiment to elucidate the observed upsurge in egg cannibalism in reaction to the conspecific neighbors.

In experiment 4 , the results revealed that the second instar larvae of $C$. carnea were more likely to eat unrelated conspecific eggs than related in no choice situations, which indicated a reluctance to cannibalize related eggs, perhaps suggesting kin recognition. Likewise, the results of video tracking bioassay also showed significant preference toward unrelated eggs in no choice environment, which resulted in more retention time in novel arm provided with unrelated eggs. Joseph et al. (1999) reported that the third instar of Asian ladybird beetle, Harmonia axyridis (Pallas), preferentially eat unrelated conspecifics instead of relatives. The neonates of ladybird predators, Coccinella transversalis and Propylea dissecta, avoided eating-related conspecific eggs and preferably consumed unrelated conspecific eggs (Omkar et al. 2004). The present study suggests $C$. carnea larvae responded differently toward related and unrelated eggs and had an adequate mechanism of kin recognition. This mechanism can be conceptually partitioned into 3 phases: production of recognition cues or labels; perception and interpretation of labels; and appropriate actions accordingly (Pfennig 1997). These cues may be intraspecific chemical odors, which have direct or indirect basis of genetic material (Roberts et al. 2003). Chemicals present on the egg surface may be influential for preference/avoidance by cannibals and may be benefitted to discriminate among related and unrelated conspecific eggs (Hemptinne et al. 2000).

\section{Conclusions}

The study demonstrated that C. carnea larvae were committed egg cannibalism even in the presence of host eggs. It may depend on the type of host eggs. Future work is needed to check the cannibalism in the presence of eggs of different hosts. Cannibalism that is controlled by the presence of conspecific is a unique behavior that may initiate density-dependent cannibalism. Likewise, it is more often related with conditions when resources are limited. The behavioral response described here might upsurge cannibalism even when resources are sufficient, augment the circumstances under which cannibalism may be effective. The study suggests that the presence of conspecific C. carnea larvae induces focal larvae to become more cannibalistic toward conspecific eggs. Furthermore, an expression of $C$. carnea larvae toward related and unrelated conspecific eggs provides the best evidence of kin recognition. Obtained data set was based on laboratory studies. An empirical research must be needed in the natural environment to address the issues like: (1) dietary qualities of host to avoid cannibalism; (2) influence of interspecific competition on cannibalism; and (3) the bases of cues or labels that limit or promote cannibalism.

\section{Abbreviations \\ ${ }^{\circ} \mathrm{C}$ : Celsius; RH: Relative humidity; cm: Centimeter; mm: Millimeter; HSD: Hon- esty significance difference.}

\section{Acknowledgements}

Not applicable.

Authors' contributions

MS planned the research project, wrote, revised and edited the manuscript. QAS helped to conduct the experiments and wrote the manuscript. MUA and IR made critical revisions to the manuscript. RM supervised the research and helped to analyze the data. All authors have read and agreed to the final version of the manuscript.

\section{Funding}

Not applicable.

Availability of data and materials

Not applicable.

\section{Declarations}

Ethics approval and consent to participate

Not applicable.

Consent for publication

Not applicable.

Competing interests

The authors declare that there is no competing interests.

Received: 7 June 2021 Accepted: 21 October 2021

Published online: 01 November 2021 


\section{References}

Arvaniti K, Fantinou A, Perdikis D (2019) Cannibalism among same-aged nymphs of the omnivorous predator Dicyphus errans (Hemiptera: Miridae) is affected by food availability and nymphal density. Eur Jo Entomol 116:302-308. https://doi.org/10.14411/eje.2019.033

Barros-Bellanda HC, Zucoloto FS (2005) Egg cannibalism in Ascia monuste in the field; opportunistic, preferential and very frequent. J Ethol 23(2):133138. https://doi.org/10.1007/s10164-004-0138-y

Barros-Bellanda HC, Zucoloto FS (2001) Influence of chorion ingestion on the performance of Ascia monuste and its association with cannibalism. Ecological Entomology 26(6):557-561. https://doi.org/10.1046/j.13652311.2001.00377.x

Gaglio G, Napoli E, Falsone L, Giannetto S, Brianti E (2017) Field evaluation of a new light trap for phlebotomine sand flies. Acta Trop 174:114-117. https://doi.org/10.1016/j.actatropica.2017.07.011

Gagné I, Coderre D, Mauffette Y (2002) Egg cannibalism by Coleomegilla maculata lengi neonates: preference even in the presence of essential prey. Ecol Entomol 27(3):285-291. https://doi.org/10.1046/j.1365-2311. 2002.00412.x

Hemptinne J-L, Lognay G, Gauthier C, Dixon A (2000) Role of surface chemical signals in egg cannibalism and intraguild predation in ladybirds (Coleoptera: Coccinellidae). Chemoecology 10(3):123-128. https://doi.org/10. 1007/PL00001813

Joseph S, Snyder W, Moore A (1999) Cannibalizing Harmonia axyridis (Coleoptera: Coccinellidae) larvae use endogenous cues to avoid eating relatives. J Evol Biol 12(4):792-797. https://doi.org/10.1046/j.1420-9101.1999. 00077.x

Kerkut G (2013) Biochemistry, vol 10. Elsevier

Lissåker M, Svensson O (2008) Cannibalize or care? The role of perceived paternity in the sand goby, Pomatoschistus Minutus. Behav Ecol Sociobiol 62(9):1467. https://doi.org/10.1007/s00265-008-0576-6

Manica A (2004) Parental fish change their cannibalistic behaviour in response to the cost-to-benefit ratio of parental care. Anim Behav 67(6):1015-1021. https://doi.org/10.1016/j.anbehav.2003.09.011

Neff BD, Sherman PW (2003) Nestling recognition via direct cues by parental male bluegill sunfish (Lepomis macrochirus). Anim Cogn 6(2):87-92. https://doi.org/10.1007/s10071-003-0166-y

Omkar PA, Gupta A (2004) Role of surface chemicals in egg cannibalism and intraguild predation by neonates of two aphidophagous ladybirds, Propylea dissecta and Coccinella transversalis. J Appl Entomol 128(9-10):691695. https://doi.org/10.1111/j.1439-0418.2004.00913.x

Pasini RA, Grützmacher AD, de Bastos PJ, de Armas FS, Bueno FA, Pires SN (2018) Side effects of insecticides used in wheat crop on eggs and pupae of Chrysoperla externa and Eriopis connexa. Phytoparasitica 46(1):115-125. https://doi.org/10.1007/s12600-018-0639-9

Pfennig DW (1997) Kinship and cannibalism. Bioscience 47(10):667-675. https://doi.org/10.2307/1313207

Pitwak J, Oliveira M, Ventura MU (2016) Development and reproductive performance of Chrysoperla externa (Neuroptera: Chrysopidae) using preys from wheat crop. Rev Colomb Entomol 42(2):118-123. https://doi.org/10. 25100/socolen.v42i2.6681

Pizzatto L, Shine R (2011) You are what you eat: parasite transfer in cannibalistic cane toads. Herpetologica 67(2):118-123. https://doi.org/10.1655/ HERPETOLOGICA-D-10-00051.1
Polis GA (1981) The evolution and dynamics of intraspecific predation. Annu Rev Ecol Syst 12(1):225-251. https://doi.org/10.1146/annurev.es.12. 110181.001301

Richardson ML, Mitchell RF, Reagel PF, Hanks LM (2010) Causes and consequences of cannibalism in noncarnivorous insects. Annu Rev Entomol 55:39-53. https://doi.org/10.1146/annurev-ento-112408-085314

Roberts JA, Taylor PW, Uetz GW (2003) Kinship and food availability influence cannibalism tendency in early-instar wolf spiders (Araneae: Lycosidae). Behav Ecol Sociobiol 54(4):416-422. https://doi.org/10.1007/ s00265-003-0646-8

Simpson J, Joncour B, Nelson WA (2018) Low levels of cannibalism increase fitness in an herbaceous tortrix moth. Behav Ecol Sociobiol 72(2):25. https://doi.org/10.1007/s00265-018-2439-0

Sohail M, Muhammad R, Soomro QA (2020) Effect of oleander aphid (Aphis nerii Boyer de Fonscolombe) on the mortality and biological parameters of green lacewing (Chrysoperla carnea Stephen). Pakistan J Zool 52(1):231. https://doi.org/10.17582/journal.pjz/2020.52.1.231.237

Sohail M, Soomro QA, Muhammad R, Asif MU, Akbar W, Ismail M (2018) Eggs exposure to low temperature reasons dwindled viability and impeded biology in green lacewing ( Chrysoperla carnea Stephen). Int J Biosci 12(5):206-214. https://doi.org/10.12692/ijb/12.5.206-214

Sohail M, Khan SS, Muhammad R, Soomro QA, Asif MU, Solangi BK (2019) Impact of insect growth regulators on biology and behavior of Chrysoperla carnea (Stephens)(Neuroptera: Chrysopidae). Ecotoxicology 28(9):1115-1125. https://doi.org/10.1007/s10646-019-02114-1

Tanahashi M, Togashi K (2009) Interference competition and cannibalism by Dorcus rectus (Motschulsky)(Coleoptera: Lucanidae) larvae in the laboratory and field. Coleopt Bull 63(3):301-310. https://doi.org/10.1649/1143.1

Tigreros N, Wang EH, Thaler JS (2018) Prey nutritional state drives divergent behavioural and physiological responses to predation risk. Funct Ecol 32(4):982-989. https://doi.org/10.1111/1365-2435.13046

Van den Beuken TP, Stockwell LW, Smallegange IM (2019) Et tu, brother? Kinship and increased nutrition lower the incidence of cannibalism in male bulb mites. Anim Behav 152:45-52. https://doi.org/10.1016/j.anbehav. 2019.04.006

Vijendravarma RK, Narasimha S, Kawecki TJ (2013) Predatory cannibalism in Drosophila melanogaster larvae. Nat Commun 4:1789. https://doi.org/10. 1038/ncomms2744

Wise DH (2006) Cannibalism, food limitation, intraspecific competition, and the regulation of spider populations. Annu Rev Entomol 51:441-465. https://doi.org/10.1146/annurev.ento.51.110104.150947

Zucoloto F (1993) Acceptability of different Brazilian fruits to Ceratitis capitata (Diptera, Tephritidae) and fly performance on each species. Braz J Med Biol Res 26(3):291-298

\section{Publisher's Note}

Springer Nature remains neutral with regard to jurisdictional claims in published maps and institutional affiliations.

\section{Submit your manuscript to a SpringerOpen ${ }^{\circ}$ journal and benefit from:}

- Convenient online submission

- Rigorous peer review

- Open access: articles freely available online

- High visibility within the field

- Retaining the copyright to your article

Submit your next manuscript at $\boldsymbol{\nabla}$ springeropen.com 